\title{
INTERPRETAÇÃO DOS DIREITOS FUNDAMENTAIS: CAMINHOS PARA A HERMENÊUTICA CONSTITUCIONAL NO BRASIL
}

\section{Eneas Romero de Vasconcelos}

Promotor de Justiça. Mestre em Direito e Estado pela Universidade de Brasília. Professor de Filosofia do Direito da FA7. eneasromero@hotmail.com

\begin{abstract}
Sumário: 1) Os direitos fundamentais no Brasil 1.1 As influências históricas das Constituições brasileiras 1.2 Os sistemas jurídicos e a justiça constitucional 1.2.1 O sistema anglo-saxão: a Constituição americana e o direito interpretado pelos Tribunais 1.2.2 O sistema romano-germânico: a intervenção e a objetividade metodológica da atividade judicial do direito constitucional alemão. 2) A interpretação dos direitos fundamentais no Brasil: caminhos.
\end{abstract}

Resumo: $O$ texto trata da interpretação dos direitos fundamentais no Brasil no modelo do Estado Democrático de Direito. Para compreender o modelo adequado para a interpretação dos direitos fundamentais na Constituição de 1988, inicia-se fazendo um histórico do desenvolvimento do modelo constitucional brasileiro, comparando a influência do modelo Americano (Common Law ejudicial review) e do modelo alemão (statute law e controle concentrado de constitucional). Ao final, trata dos caminhos para a interpretação dos direitos fundamentais no Brasil hoje.

Palavras-chave: Direito Constitucional; Direitos Fundamentais; Constituição; Interpretação; Brasil.

"algo de novo está emergindo no Brasil. Talvez algo entre o modelo romano-germânico do Brasil (inspirado no modelo alemão) da tradição de codificação e sistematização da jurídica e o modelo americano do case law, este 'algo' irá adquirir a sua forma."'

1 Paráfrase à seguinte afirmação de SCHLINK: "Something new is emerging in Germany. Perhaps somewhere between the German tradition of codified, systemized law and the American idea of case law, this 'something' will take its form." SCHLINK, Bernhard. German constitutional culture in transition. In: ROSENFELD, Michel (ed.). Constitutionalism, Identity, Difference, and Legitimacy: Theoretical Perspectives, p. 222. 


\section{Os DIREITOS FUNDAMENTAIS NO BRASIL}

O jurista NORBERTO BOBBIO denomina a atual fase do Estado de Direito de "Era dos Direitos". Nesta nova era, direitos humanos, garantidos e protegidos, são pressuposto da democracia e da paz $^{2}$ e passam a integrar os ordenamentos jurídicos estatais (especialmente as Constituições) e as cartas de direitos humanos internacionais, reconhecidas e ratificadas pelas nações ocidentais e orientais.

Mais do que simples textos jurídicos, os direitos fundamentais ${ }^{3}$ fazem parte do discurso quotidiano de cidadãos, políticos e juristas de países ocidentais e orientais, desenvolvidos e subdesenvolvidos, embora encobertos por enormes divergências, ambigüidades e contradições.

Mesmo entre países do mundo ocidental e desenvolvido (e dentro deles mesmo) ainda existe enorme divergência na prática constitucional, inclusive em temas capitais, como a pena de morte, o aborto, a eutanásia, o racismo. ${ }^{4}$

2 O desrespeito sistemático aos direitos fundamentais é incompatível com o Estado Democrático de Direito. A relação de necessidade entre democracia e respeito aos direitos humanos é bem explicitada por Bobbio: "Direitos do homem, democracia e paz são três momentos necessários do mesmo movimento histórico: sem direitos do homem reconhecidos e protegidos, não há democracia; sem democracia, não existem as condições mínimas para a solução pacífica dos conflitos." BOBBIO, Norberto. A Era dos Direitos, p. 1.

3 LUÑO explica com clareza a distinção de positivação entre direitos humanos e fundamentais: "Los derechos humanos suelen venir entendidos como un conjunto de faculdades e instituciones que, en cada momento histórico, concretan las exigências de la dignidad, la libertad y la igualdad humanas, las quales deben ser reconecidas positivamente por los ordenamientos juridicos a nivel nacional e internacional. En tanto que com la noción de los derechos fundamentales se tiende a aludir aquellos derechos humanos garantizados por el ordenamiento jurídico positivo, en la mayor parte de los casos em su normativa constitucional, y que suele gozar de uma tutela reforzada." (LUÑO, Antonio-Enrique Pérez. Los derechos fundamentales, p. 46). O termo direitos humanos tem sua origem controvertida, embora possa situar-se, com LUÑO, seu surgimento no início do iluminismo: "Para algunos, los derechos humanos suponen una constante histórica cuyas raíces se remontan a las instituciones y el pensamiento del mundo clásico. Otros, por el contrario, sostienen que la idea de los derechos humanos nace con la afirmación cristiana de la dignidad moral del hombre em cuanto persona. Frente a estos últimos, a su vez, hay quien afirma que el cristianismo no supuso un mensaje de libertad, sino más bien una aceptación conformista del hecho de la esclavitud humana. Sin embargo, lo más frecuente es considerar 'la primera aparición dela idea de derechos del hombre [...] tuvo lugar durante la lucha de los pueblos contra el régimen feudal y la formación de las relaciones burguesas" (LUÑO, Antonio-Enrique Pérez. Derechos Humanos, Estado de Derecho y Constitucion, p. 23) Já a terminologia direito fundamentais, embora hoje se aproxime da tradição jurídica alemã em empregar o termo Grundrechte, especialmente após a Lei Fundamental de 1949, teve origem, também, na França: “El término 'derechos fundamentales', droits fondamentaux, aparece en Francia hacia 1770 em el movimento político y cultural que condujo a la Declaración de los Derechos del Hombre y del Ciudadano de 1789. La expresión há alcanzado luego especial relieve em Alemania, donde bajo el título de los Grundrechte se há articulado el sistema de relaciones entre el individuo y ele Estado, en cuanto fundamento de todo el orden jurídico-político. Este es su sentido em la Grundgesetz de Bonn de 1949. (LUÑO, Antonio-Enrique Pérez. Derechos Humanos, Estado de Derecho y Constitucion, p. 30) Na doutrina, direitos humanos são dotados normalmente de cunho mais internacional e direitos fundamentais com cunho mais nacional, constitucional. Autores que tratam, no Brasil, do direito interno usam normalmente a terminologia direitos fundamentais; os que tratam do direito internacional preferem utilizar direitos humanos. Utilizam a expressão direitos fundamentais constitucionalistas, como: MENDES, Gilmar Ferreira. . Hermenêutica Constitucional e Direitos Fundamentais, p. 197-210; BONAVIDES, Paulo. Curso de Direito Constitucional, p. 514-530; SARLET, Ingo Wolfgang. A eficácia dos direitos fundamentais, p. 36. Utilizam a expressão direitos fundamentais internacionalistas,como: TRINDADE, Antônio Augusto Cançado. Tratado de Direito Internacional dos Direitos Humanos, volume 1, p. 17-58. 
Situações difíceis (hard cases, DWROKIN), como o caso do aborto, seriam tratadas de modo bem diverso por autores com diferentes compreensões do direito pressuposto. As diferentes compreensões dos direitos fundamentais, mesmo quando não reveladas em cada pesquisa, podem, certamente, ser inferidas, o que levou DWORKIN a afirmar que "o voto de qualquer juiz é, em si, uma peça de filosofia do direito, mesmo quando a filosofia está oculta e o argumento visível é dominado por citações e listas de fatos."

Se no mesmo Estado, diferentes interpretações não são apenas possíveis mas freqüentes, o que se pode dizer da interpretação dos direitos fundamentais nas diferentes nações e especialmente entre aquelas com maiores diferenças culturais?

À semelhança normativa dos textos constitucionais opõem-se as práticas jurídicas e sociais dos países supostamente defensores dos direitos humanos. Se do ponto de vista normativo há grande semelhanças (e por vezes coincidência dos textos, especialmente dos tratados, embora parcialmente, também, das Constituições), na interpretação a situação é diferente.

Neste texto, o objetivo não é discutir as diferenças entre os direitos fundamentais nos diversos países, nem tampouco as diferentes compreensões de direitos fundamentais no Estado Democrático de Direito. O objetivo é mais modesto: procurar indicar caminhos para a interpretação dos direitos fundamentais no Brasil pelos Tribunais.

No Estado Democrático de Direito, a interpretação dos Tribunais, especialmente das cortes constitucionais adquire especial importância. Na teoria dos direitos fundamentais, o estudo da jurisprudência é tão importante quanto o estudo do texto da Constituição, em razão da natureza aberta, polissêmica e indeterminada destas normas. Os Tribunais Constitucionais acabam determinando, em grande medida, o que são os direitos fundamentais em um determinado ordenamento jurídico concreto, como afirma ALEXY:

"Lo que hoy son los derechos fundamentales es definido, principalmente, sobre la base de la jurisprudencia del Tribunal Constitucional Federal. La ciencia de los derechos fundamentales - no obstante la controversia de la fuerza de las decisiones del Tribunal Constitucional Federal - se ha convertido, en una apreciable medida, en una ciencia de la jurispurdencia constitucional ." 6

\footnotetext{
4 Nos Estados Unidos da América, por exemplo, autores mais conservadores consideram a decisão que constitucionalizou o abortou uma clara afronta à Constituição. Os juízes que decidiram o leading case Roe vs. Wade certamente não achavam que estavam desrespeitando a Constituição, mas pensavam sinceramente que o direito à personalidade privada abrange o direito de a mulher decidir, autonomamente, abortar o feto na fase inicial da gravidez. Para a compreensão resumida da constitucionalização do aborto nos Estados Unidos, inclusive nos caso posteriores ao precedente Roe vs. Wade ver: LOCKHART, William B.et al. The Americna Constitution: cases, coments, questions, p. 508-575.
}

5 DOWORKIN, Ronald. O Império do Direito. p. 113.

6 ALEXY, Robert. Teoría de los Derechos Fundamentales, p. 23. 
A compreensão da atual situação dos direitos fundamentais no Brasil exige algo mais: o resgate das influências históricas. Em seu desenvolvimento o direito constitucional brasileiro sofreu as seguintes influências mais marcantes: inglesa e francesa (notadamente até a Constituição de 1824), americana (a partir da Constituição republicana de 1891), espanhola, portuguesa, alemã e outras (especialmente a partir da Constituição de 1988). As influências históricas revelam a existência de dois sistemas jurídicos no Ocidente que influenciam mais diretamente o direito constitucional brasileiro: 1) o sistema americano de controle difuso da constitucionalidade do judicial review; 2) o sistema europeu das Cortes Constitucionais e do controle abstrato da constitucionalidade das normas por Tribunais situados fora do clássico sistema tripartite de poderes.

\subsection{AS INFLUÊNCIAS HISTÓRICAS DAS CONSTITUIÇÕES BRASILEIRAS}

A compreensão dos direitos fundamentais no Estado Democrático de Direito não se constrói a partir da Constituição de 1988, que é apenas o ponto de chegada da pesquisa, mas pressupõe uma história constitucional que a precede e que permeia a compreensão jurídica contemporânea em sua história efeitual. ${ }^{7}$

A reconstrução, sucinta e simplificada, das influências históricas do constitucionalismo brasileiro possibilita compreender as influências atuais do direito brasileiro e daí as referências ao direito estrangeiro feitas na presente pesquisa. Neste diapasão, pode-se afirmar com BONAVIDES que:

\footnotetext{
"Sem uma acurada reflexão acerca desse processo que nem sempre eliminou a maior parte dos influxos recebidos em cada fase ultrapassada senão que os levou na devida conta ou às vezes os incorporou de forma cumulativa, não se pode compreender os rumos constitucionais contemporâneos, presentes à realidade brasileira, sobretudo depois da promulgação da Carta de 5 de outubro de 1988."
}

BONAVIDES divide a história constitucional brasileira, sobre a perspectiva das influências estrangeiras em três fases, ${ }^{9}$ a saber: 1) o constitucionalismo do império, em que se destaca a presença da inspiração francesa e inglesa; 2) o constitucionalismo da primeira república, em que ocorreu adoção do modelo americano, com o federalismo, o presidencialismo e o controle difuso de

7 Para a compreensão da história ver: GADAMER, Hans-Georg. Verdade e Método. Traços fundamentais de uma hermenêutica filosófica, p. 449-458.

8 BONAVIDES, Paulo. Curso de Direito Constitucional, p. 327.

9 "Quem se propuser a uma análise em profundidade da evolução constitucional do Brasil não terá dificuldade em distinguir três fases históricas perfeitamente identificáveis em relação aos valores políticos, jurídicos e ideológicos que tiveram influxo preponderante na obra de caracterização formal das instituições: a 
constitucionalidade; 3) o constitucionalismo do Estado social com influência das Constituições alemãs de Weimar e de Bonn, que perdura até hoje.

No constitucionalismo do império, a presença da inspiração francesa e inglesa é indelével. Na organização do Estado, o Brasil adotou o modelo de separação de poderes de BENJAMIM CONSTANT, que, reformulando a proposta de MONTESQUIEU de separação de três poderes, adicionou um quarto poder: $\mathrm{o}$ poder moderador, que na prática teve proeminência em relação aos demais.

O Brasil incorporou formalmente à Constituição imperial (inclusive com primazia em relação às demais normas ${ }^{10}$ ) os direitos e garantias individuais e os direitos políticos com inspiração na Constituição francesa de 1791. Neste período, os ideais liberais do constitucionalismo francês, pós-revolução de 1789, e inglês foram marcantes para o constitucionalismo brasileiro, especialmente para a sua Constituição formal. ${ }^{11}$

No constitucionalismo da primeira república, a influência mais evidente do constitucionalismo liberal Europeu foi substituída pela adoção do constitucionalismo liberal americano, com a mudança da forma de Estado (do Estado Unitário para o Federal), da forma de Governo (o Presidencialismo em substituição ao Parlamentarismo) e do sistema de controle entre os poderes com a instituição do controle difuso de constitucionalidade. ${ }^{12}$

No constitucionalismo do Estado social, ocorre a incorporação das normas protetoras do Estado social sobre a influência do constitucionalismo alemão das Constituições de Weimar e Bonn. Inicialmente, a influência do constitucionalismo alemão é observada na Constituição de 1934, que foi seguida de sucessivas e graves crises institucionais, marcadas pelo período do Estado Novo e pelo advento de nova Constituição, a Constituição de 1937, conhecida como "a polaca", por sua inspiração no modelo fascista polonês. ${ }^{13}$

primeira, vinculada ao modelo constitucional francês e inglês do século XIX; a segunda, representando já uma ruptura, atada ao modelo norte-americano e, finalmente, a terceira, em curso, em que se percebe, com toda a evidência, a presença de traços fundamentais presos ao constitucionalismo alemão do corrente século." (BONAVIDES, Paulo. Curso de Direito Constitucional, p. 327) .

${ }^{10}$ Os artigos 267 e 268 da Constituição de 1824 dispunham, respectivamente: "É só constitucional o que diz respeito aos limites e atribuições respectivas dos poderes políticos e aos direitos políticos e individuais" e "Tudo o que não é constitucional pode ser alterado pelas legislaturas ordinárias, concordando dois terços de cada uma das salas".

${ }^{11} \mathrm{Na}$ prática, as promessas do constitucionalismo liberal foram negadas em grande parte nos países de origem, em que os direitos liberais apenas garantiam a proteção de direitos humanos para uma minoria que poderia exercê-lo, visto que a maioria era excluída formalmente (as mulheres não tinham direitos políticos, por exemplo) ou materialmente por um sistema capitalista de exclusão social. No Brasil, a frustração das promessas do constitucionalismo do século XVIII foi ainda mais marcante, especialmente em face da abolição tardia da escravidão. Para a compreensão da história constitucional do Brasil, ver: BONAVIDES, Paulo \& ANDRADE, Paes de. História Constitucional do Brasil. Brasília: OAB editora, 2002.

${ }^{12}$ Nesta fase, de grandes e freqüentes crises políticas, houve freqüentes desrespeitos aos direitos fundamentais com a instituição da censura e freqüentes intervenções nos estados membros. 
Golpes, desrespeito aos direitos fundamentais, freqüentes crises políticas e rupturas institucionais caracterizam este período. Foram outorgadas duas Constituições (1937 e 1969) e vários atos de natureza constitucional foram emanados do Poder Executivo, como os atos institucionais do período de ditadura militar. ${ }^{14}$

No período denominado por BONAVIDES de constitucionalismo do Estado social o mesmo autor verifica a ascendência mais marcante do constitucionalismo tedesco, representado pela Lei Fundamental de Bonn de 1949, e pelos seus direitos sociais. O constitucionalista cearense afirma:

"Na técnica, na forma e na substância da matéria pertinente a direitos fundamentais, a derradeira Constituição do Brasil se acerca da Lei Fundamental alemã de 1949, e até ultrapassa em alguns pontos.

Segue e incorpora também a mesma tradição de Weimar em dar proeminência ao social. (...)

Abrindo seus primeiros capítulos com a matéria dos direitos e garantias fundamentais, até nessa particularidade a Constituição brasileira de 1988 se avizinhou da Lei Fundamental de Bonn." ${ }^{15}$

Apesar da importância do bem sucedido constitucionalismo alemão após o advento da Lei Fundamental de Bonn, foram, também, muito importantes outras contribuições históricas na Constituição de 1988. Destacam-se, especialmente, a influência do constitucionalismo de Portugal (após a revolução dos cravos e a Constituição de 1976) e da Espanha (após a redemocratização com o advento da monarquia constitucional e da Constituição de 1978), países que possuem semelhança histórica e cultural com o Brasil, além de terem passado por um processo de redemocratização e estabilidade política após um longo e recente período autoritário.

Na verdade, no periodo constitucional do Estado Democrático de Direito, como poderia ser denominado o período posterior à Constituição de 1988 , confluem todas as influências históricas anteriores (inglesa, francesa, americana

\footnotetext{
${ }^{13}$ Sobre os modelos constitucionais que inspiraram a carta de 1937, BONAVIDES qualifica de exagerada a identificação com a Constituição polonesa, embora identifique um pensamento autoritário: "Atribuem-se a vários fatores e diversas fontes de inspiração a Carta de 1937. Seguramente, a influência maior foi a da Constituição da Polônia, o que permitiu aos críticos e analistas da época denomina-la maliciosamente de 'A Polaca'. Mas é indispensável acrescentar a essa fonte inspiradora, a influência do fascismo de Mussolini vitorioso na Itália em 1922, do nazismo implantado por Hitler na Alemanha, com desculpa de prevenção da estabilidade econômico-financeira ainda sob o impacto da crise mundial de 1929." (BONAVIDES, Paulo \& ANDRADE, Paes de. História Constitucional do Brasil, p. 345-346).

${ }^{14}$ Para uma compreensão política mais ampla do período militar ver: a) GASPARI, Elio. O sacerdote e o Feiticeiro: a ditadura derrotada. São Paulo: Companhia das Letras, 2003; b) GASPARI, Elio. A ditadura envergonhada. São Paulo: Companhia das Letras, 2003; c) GASPARI, Elio. A ditadura escancarada. São Paulo: Companhia das Letras, 2003.

${ }^{15}$ BONAVIDES, Paulo. Curso de Direito Constitucional, p. 335.
} 
e alemã), agregando-se outras experiências democráticas, em que a ascendência espanhola e portuguesa são mais marcantes, mas, também, poderia destacar-se a italiana, dentre tantas outras.

Neste novo período, posterior à Constituição democrática de 1988, passou a preponderar o paradigma do Estado Democrático de Direito em substituição aos ultrapassados paradigmas liberal e social. No novo paradigma, ocorre uma reformulação da relação de concorrência entre direitos humanos e soberania e autonomia pública e privada. Os direitos humanos têm sua importância reafirmada no modelo do Estado Democrático de Direito, em que passa a haver uma convergência entre direitos humanos e direitos fundamentais.

Embora direito interno constitucional e direito internacional continuem a ser disciplinas diferentes, cada uma com um sistema próprio de proteção, a aproximação entre ambas verifica-se, claramente, no âmbito dos direitos humanos internacionais e dos direitos fundamentais constitucionais, ${ }^{16} \mathrm{com}$ incremento progressivo, o que permite, até mesmo, uma percepção de confluência e de complementaridade entre elas, como sintetiza CANÇADO TRINDADE:

\begin{abstract}
“Afastada, no presente domínio, a compartimentalização, teórica e estática da doutrina clássica, entre o direito internacional e o direito interno, em nossos dias, com a interação dinâmica entre um e outro neste âmbito de proteção, é o próprio direito que se enriquece e se justifica, - na medida em que cumpre a sua missão última de fazer justiça. No presente contexto, $o$ direito internacional e o direito interno interagem e se auxiliam mutuamente no processo de expansão e fortalecimento do direito de proteção do ser humano. Nestes anos derradeiros a conduzir-nos ao final do século, é alentador ao menos constatar que o direito internacional e $o$ direito interno caminham juntos e apontam na mesma direção, coincidindo no propósito básico e último de ambos da proteção do ser humano."17
\end{abstract}

No constitucionalismo do Estado Democrático de Direito, as mesmas questões são discutidas pela sociedade e se revelam no direito constitucional (sendo incorporados na Constituição pelo Poder Constituinte) e na formação do Estado pelos poderes constituídos, especialmente no Poder Legislativo, em que a elaboração de leis que protegem ou restringem direitos fundamentais é uma tônica de seu quotidiano, e no Poder Judiciário, que passou a decidir as questões constitucionais mais relevantes.

${ }^{16}$ Para a compreensão da relação entre direitos humanos internacionais e direitos fundamentais constitucionais na Constituição de 1988 ver: GALINDO, George Rodrigo Bandeira. Tratados internacionais de direitos humanos e Constituição brasileira, p. 73-136.

17 TRINDADE, Antônio Augusto Cançado. Tratado de Direito Internacional dos Direitos Humanos, volume 1, p. 445. 
Hoje, questões controversas (como a constitucionalidade do aborto, da pena de morte, da eutanásia, os limites à liberdade de expressão e as ações afirmativas) são decididas pelas Cortes Constitucionais dos diversos Estados Democráticos de Direito. Até mesmo a Suprema Corte americana, tradicionalmente infensa às influências estrangeiras, começa a admiti-la:

"Um sinal do entrecruzamento-fertilizado e do diálogo no direito constitucional é a crescente prática das cortes supremas e constitucionais em citar instrumentos internacionais e decisões estrangeiras. Muitas novas cortes, como a da África do Sul, e muitas outras cortes interpretando instrumentos constitucionais relativamente novos, como no Canadá, citam rotineiramente outras jurisdições constitucionais. Até alguns juízes da Suprema Corte dos Estados Unidos, mais velha e mais insular do que a respiração, citaram casos e exemplos estrangeiros." ${ }^{18}$

Na prática judicial e na doutrina brasileira, percebe-se claramente a influência destes modelos, que refletem em última análise as influências já reveladas na histórica constitucional brasileira, antiga e recente. $\mathrm{O}$ estudo dos direitos fundamentais procurou seguir esta linha de influência histórica, embora possam notar-se ausências importantes. ${ }^{19}$

Com esteio nestas influências do direito estrangeiro no direito brasileiro, deve-se buscar compreender os direitos fundamentais no modelo de Estado Democrático de Direito no Brasil após a Constituição de 1988.

\subsection{Os SISTEMAS JURÍDICOS E A JUSTIÇA CONSTITUCIONAL}

Da exposição dos sistemas jurídicos estrangeiros, percebem-se, claramente, dois modelos mais relevantes seguidos no Ocidente, inclusive para o Brasil: 1) o sistema jurídico romano-germânico, em que a influência da dogmática constitucional alemã e da jurisprudência do Tribunal Constitucional Federal destaca-se; 2) o sistema jurídico

18 DORSEN, Norman et al. Comparative Constitutionalism: cases and materials, preface, p. iii, no original, "One sign of the cross-fertilization and dialogue in constitucional law is the increasing practices of supreme and constitutional courts to cite to international instruments and foreign decisions. Many newer courts, as in South Africa, and many courts interpreting relatively new constitutional instruments, as in Canada, routinely cite to other jurisdictions. Even some justices of the U.S. Supreme Court, older and more insular that its breathren, have cited foreign cases and foreign examples."

19 A prática constitucional em relação aos direitos fundamentais tentou seguir o critério de influências históricas na linha de BONAVIDES, embora não se negue que outros países enriqueceriam a pesquisa e a dificultariam também. Diante da abrangência, foram excluídos os países da América Latina, alguns países Europeus importantes (como a Itália e o leste Europeu, recentemente democratizado), os países da África (a experiência da África do Sul certamente seria útil) e da Ásia. Desde já, pede-se desculpa ao leitor, mas o estudo de outras realidades constitucionais, apesar de sua importância, sobrecarregaria ainda mais a pesquisa. 
anglo-saxão, em que sobreleva a prática constitucional americana e a experiência de mais de dois séculos de sua Suprema Corte. ${ }^{20}$

Ambos os sistemas adotam formas diferentes de pensar o direito. No sistema romano-germânico, prepondera a preocupação com a sistematização doutrinária e a proeminência do direito legislado. No sistema anglo-saxão, os precedentes judiciais possuem maior importância.

A diferença entre os sistemas, revela-se, de igual modo, em seus respectivos modelos de justiça constitucional. Os Estados Unidos possuem um controle difuso de constitucionalidade em que a Suprema Corte é encarregada de dar a última palavra. ${ }^{21}$ A Europa Continental, representada pela Alemanha com seu Tribunal Constitucional, adotou um modelo abstrato e concentrado de constitucionalidade, segundo a formulação kelseniana. ${ }^{22}$

Apesar da clara distinção entre a construção dos modelos de Justiça Constitucional, existe hoje uma aproximação entre ambos os modelos, que se revela no fato de a decisão das Cortes Supremas, nos Estados Unidos e na Alemanha, darem a decisão definitiva sobre a constitucionalidade das leis de modo a encerrar a discussão da questão jurídica até que volte a ser enfrentada novamente pelo Tribunal. ${ }^{23}$

$\mathrm{Na}$ verdade, mais do que uma aproximação entre os modelos, pode-se afirmar que existe uma influência recíproca entre as Cortes Constitucionais dos países com diferentes tradições. O Bundesverfassungsgericht utiliza as decisões da Suprema Corte ${ }^{24}$ e até à Suprema Corte, antes avessa a qualquer influência, já citou decisão da Corte Constitucional alemã. ${ }^{25}$

${ }^{20}$ Sobre a prática constitucional este artigo procura seguir caminho semelhante ao indicado pelo constitucionalista RODRIGO KAUFMANN: KAUFMANN, Rodrigo de Oliveira. Dimensões e perspectivas da eficácia horizonta dos direitos fundamentais: possibilidades e limites de aplicação no direito constitucional brasileiro. Dissertação (Mestrado em Direito e Estado), Universidade de Brasília, Brasília, 2003.

${ }^{21} \mathrm{O}$ precedente que marca o início da judicial review of legislation nos Estados Unidos é o famoso caso Marbury v. Madison, que remonta ao ano de 1803. Para compreender o caso ver: LOCKHART, William B.et al. The American Constitution: cases, comments, questions, p. 1-17

${ }^{22}$ Embora o controle de constitucionalidade na Europa já tivesse sido proposto algumas vezes, só foi instituído na Europa a partir do século XX com o modelo kelseniano de controle de constitucionalidade abstrata, que foi adotado inicialmente na Áustria e posteriormente em outros países, como Alemanha, Itália, Portugal e Espanha. Para compreender a formulação de KELSEN ver: KELSEN, Hans. Quién debe ser el defensor de la Constitución? Madrid: Editorial Tecnos S.A., 1995. Para uma comparação entre o modelo Alemão e o modelo brasileiro de controle abstrato de constitucionalidade ver: MENDES, Gilmar Ferreira. Jurisdição Constitucional: o controle abstrato de normas no Brasil e na Alemanha, p. 3-44. Para a compreensão do modelo americano e Europeu, sobretudo austríaco a alemão, ver: CAPPELLETTI, Mauro. $O$ controle judicial de constitucionalidade das leis no direito comparado, p. 66-114.

${ }^{23}$ Embora a Suprema Corte decida o caso concreto em última instância, a decisão terá força vinculante para todos os Tribunais do país e acaba por encerrar uma discussão da constitucionalidade da lei em tese em que o caso funciona muito mais como pretexto para resolver a controvérsia jurídica.

${ }^{24}$ A doutrina Constitucional alemão estuda com freqüência a doutrina a jurisprudência americana, o que leva o constitucionalista alemão BERNARD SCHLINK até mesmo a admitir a possibilidade de que a Alemanha 
Inicialmente, o Brasil adotou um modelo de controle difuso de constitucionalidade. $\mathrm{O}$ modelo abstrato passou a ser adotado de modo gradativo e cumulativo com o concreto até adquirir proeminência a partir da Constituição de 1988 com a ampliação do rol de legitimados para propor ações diretas de constitucionalidade. ${ }^{26}$ Com o advento da emenda que instituiu a ação declaratória de constitucionalidade, a sua posterior regulamentação ao lado da ação direta, e a regulamentação da ação de descumprimento de preceito fundamental a ênfase no controle concentrado tornou-se mais evidente. ${ }^{27} \mathrm{~A}$ emenda constitucional, conhecida como reforma do judiciário, que instituiu a súmula vinculante e a argüição de relevância tornou a concentração do sistema ainda mais marcante.

Na própria evolução do sistema de controle de constitucionalidade, inclusive na progressiva concentração do sistema, já se percebem as influências dos modelos alemão e americano. A ascendência estrangeira ultrapassa o modelo de controle de constitucionalidade adotado e se manifesta amplamente na história constitucional brasileira: na construção teórica e doutrinária, na prática jurisprudencial e, de modo mais profundo, na própria formação do constitucionalismo brasileiro. Neste contexto, o desvelamento das influências americana e alemã é uma necessidade do direito constitucional brasileiro atual.

As experiências constitucionais, americana e alemã, revelam, mais do que a concorrência entre sistemas judiciais (controle concentrado v. controle difuso;

passe a ter o constitucionalismo americano como a influência decisiva apta a guiar os novos rumos do direito naquele país: "The relationship between constitutional scholarship and the Bundesverfassungsgericht will develop in one of these two directions. The first direction has tradition on its side. In the second, one sees traits of what a Europena seen in looking at the United States and the relationship betwween American constitutional scholarship and the Supreme Court. This image of the United States incorporates a view that the American public particpates more in the debate on constitutional legal and political questions, constitucional decision making, and appointments to the Supreme Court." SCHLINK, Bernhard. German constitutional culture in transition. In: ROSENFELD, Michel (ed.). Constitutionalism, Identity, Difference, and Legitimacy: Theoretical Perspectives, p. 222.

${ }^{25}$ DORSEN, ROSENFELD, SAJÓ e BAER citam casos em que a Suprema Corte americana utilizou experiências e decisões estrangeiras: "For example, in his dissent in Printz v. United States, 521 U. S. 898 (1997), Justice Stephen Breyer referred to German federalism in discussing the constitutional limits of U. S. federal power. More recentely, Justice John Paul Steven's opinion for teh Court in Atkins v. Virginia cited to a brief of the European Union as amicus curiae in a related case, pointing out that 'within the world community, the imposition of the death penalty for crimes committed by mentally retarded offenders is overwhelmingly disapproved.' 122 Sup. Ct. 2242, 2249 n. 21 (2002)." (DORSEN, Norman et. al. Comparative Constitutionalism: cases and materials, preface, p. iii).

${ }^{26}$ A ênfase no controle abstrato foi ressaltada por GILMAR FERREIRA MENDES: "A Constituição de 1988 reduziu o significado do controle de constitucionalidade incidental ou difuso, ao ampliar, de forma marcante, a legitimação para propositura da ação direta de inconstitucionalidade (CF, art. 103), permitindo que, praticamente, todas as controvérsias constitucionais relevantes sejam submetidas ao Supremo Tribunal Federal mediante processo de controle abstrato de normas." MENDES, Gilmar Ferreira. Direitos Fundamentais e Controle de Constitucionalidade: estudos de direito constitucional, p. 252.

${ }^{27}$ Não só na Constituição de 1988, mas depois dela a tendência a concentração tem acentuado-se, tanto com novas emendas, como com a legislação infraconstitucional e na jurisprudência do Supremo Tribunal Federal. 
common law v. statute law), divergências mais profundas na compreensão do direito constitucional e do papel da Constituição. ${ }^{28}$

$\mathrm{Na}$ verdade, as diferentes formas de interpretar a Constituição decorrem de dois Estados com formações diferentes, que se refletiram diretamente nos respectivos modelos constitucionais. Como demonstram SCHLINK e JACOBSON, no direito constitucional americano as disputas constitucionais partem sempre da idéia de superioridade da Constituição elaborada pelos pais fundadores, pois "a revolução americana estabeleceu acima de qualquer desafio prático que o governo somente é concebível como governo constitucional." 29

Já o direito constitucional alemão foi concebido a partir da idéia de limitação do Poder do Estado, pois como afirmam SCHLINK e JACOBSON: "O estado Alemão, por contraste, precede a constituição. Precede historicamente o estado como objeto da vontade e do poder do monarca estava lá muito antes de qualquer constituição estruturá-lo ou fundá-lo o curso da história guiou o pensamento jurídico. Até a República Federal (Bundesrepublik) a constituição era entendida não como fundadora ou estruturadora do estado, mas muito mais como formadora e limitadora de poderes hereditariamente ilimitados de uma organização política existente. A constituição derivava sua legitimidade do Estado, não o estado da constituição. Esta compreensão apenas mudou com a República Federal, sob a Lei Fundamental de 1949 (Grundgesetz)." 30

Os diferentes modos de compreensão da relação entre governo e Constituição nestes países moldaram formas diferenciadas de interpretação do direito constitucional, que, por sua grande influência (inclusive no Brasil, como se viu), precisam ser melhor explicadas.

${ }^{28}$ ROSENFELD sintetiza a formação do constitucionalismo francês, americano e alemão: "Em resumo, no modelo Alemão a constituição deve dar expressão à identidade nacional prevalecente; no Francês, transformar e redirecionar uma identidade nacionalidade já existente; e no Americano, deve apresentar as características essenciais de uma nação ainda por ser formada." No original: "In short, in the German model the constitution is supposed to give expression to a prevailing national identity; in the French, to transform and redirect na existing national identity; and in the American, to lay down the essential characteristics of the identity of a nation yet to be formed." (ROSENFEL, Michel. Constitution-making, identity building, and peaceful transformation to democracy: theoretical reflection inspired by the spanish example. In: DORSEN, Norman et. al. Comparative Constitutionalism: cases and materials, p.43.

29 "The American Revolution estabilished beyond practical challenge that government is conceivable only as constitutional government." JACOBSON, Arthur J. \& SCHLINK, Bernhard. Introduction. Constitutional Crisis. The Germanl and the American Experience. IN: JACOBSON, Arthur J. \& SCHLINK, Bernhard (ed.). Weimar: a jurispurdence of crisis, p. 1.

${ }^{30}$ No original: "The German state, by contrast, preceds the constitution. It does so historically the state as object of the monarhc's will and power was there before any consitution could frame or found it and the course of history has guided legal thinking. Until the Federal Republic (Bunsdesrepublik) the constitution was understood not as founding and framing the state, but rather as shaping and limiting the inherently unlimited powers of an already existing political organization. The constitution derived its legitimacy from 


\subsubsection{O Sistema ANGlO-SAXÃo: A CONSTITUiÇão AMERICANA E O DIREITO INTERPRETADO PELOS TRIBUNAIS ${ }^{31}$}

A história da Constituição americana coincide com a história dos Estados Unidos da América. Ela foi desafiada por três crises sem jamais ter sido abandonada ou mesmo colocada em "cheque". ${ }^{32}$ As crises do Estado americano não resultaram em crises constitucionais. Delas a Constituição saiu reafirmada e fortalecida. SCHLINK e JACOBSON resumem esta situação:

"Que a crise do Estado devesse resultar em uma crise da fundação e da estrutura do direito não é algo evidente em si mesmo; certamente a experiência americana demonstra o contrário. Crises no Estado americano nunca levaram as elites políticas a questionar a legitimidade constitucional de seu governo. Até mesmo a extraordinária luta que levou à Guerra Civil não causou dúvidas sobre a legitimidade do governo em si mesma. Elas eram a ordinária, mesmo que ultimamente violenta, luta da interpretação constitucional, mais do que uma tentativa de sustentar princípios de organização política fundamentalmente diferentes." ${ }^{" 33}$

Na reafirmação da primazia da Constituição sobre o governo a Suprema Corte desempenhou um papel importante na história americana. Desde o caso Marbury v. Madison, a Corte tomou para si a responsabilidade de decidir o conflito entre os poderes do Estado e assumiu o poder de dar a última palavra no conflito entre a lei e a Constituição, podendo julgar inconstitucional qualquer lei.

Neste contexto, a Suprema Corte americana transformou-se em uma caixa de ressonância dos conflitos constitucionais que refletiam, na verdade, profundos conflitos sociais e políticos. Alguns dos principais debates políticos americanos eram levados para a Suprema Corte, que desenvolveu um papel chave

the state, not the state from the constitution. This understanding has shifted only in Federal Republic, under the Basic Law of 1949 (Grundgesetz)." JACOBSON, Arthur J. \& SCHLINK, Bernhard. Introduction. Constitutional Crisis. The German and the American Experience. IN: JACOBSON, Arthur J. \& SCHLINK, Bernhard (ed.). Weimar: a jurisprudence of crisis, p. 1-2.

${ }^{31}$ A Inglaterra, outra representante do sistema do common law, possui a democracia constitucional mais antiga e estável do mundo, mas as peculiaridades e complexidade de seu modelo constitucional tornaram difícil a sua transposição para outros Estados Democráticos, razão pela qual não foi analisada, embora se reconheça sua inegável importância.

32 JACOBSON e SCHLINK referem-se a três crises: 1) a primeira, na década de 1780, versava sobre o problema da unidade; 2) a segunda, que resultou na Guerra Civil, ocorreu por conta da escravidão; 3 ) a terceira, no período do New Deal, envolveu o conflito entre liberdade individual e o poder do governo para intervir em favor do povo (JACOBSON, Arthur J. \& SCHLINK, Bernhard. Introduction. Constitutional Crisis. The German and the American Experience. IN: JACOBSON, Arthur J. \& SCHLINK, Bernhard (ed.). Weimar: a jurisprudence of crisis, p. 21).

33 "That a crisis of the state should result in a crisis of the law framing and founding it is not self-evident; certainly the American experience is to the contrary. Crises of the American state haver never led political elites to question the legitimacy of constitutional government. Even the extraordinary struggles leading 
nos principais momentos da história americana: no conflito racial (a escravidão, a segregação e as ações afirmativas), no exercício da liberdade de expressão e da privacidade, nos conflitos federativos, na implementação de políticas públicas, no direito à vida (pena de morte, aborto e eutanásia) etc. ${ }^{34}$

No direito constitucional americano, os problemas jurídicos eram tratados, também, como problemas políticos e sociais e a interpretação constitucional era permeada por fortes tensões em que a Suprema Corte era chamada para dar a última palavra.

Um sistema constitucional formado no contexto de um debate democrático propiciou o surgimento de uma justiça constitucional cujas decisões refletiam as posições expressas na discussão pública. A interpretação constitucional torna-se, então, uma forma de garantia da democracia, pois "em uma democracia deliberativa, uma das principais funções da Constituição é proteger não a regra da maioria, mas a moralidade interna da democracia, vista em termos deliberativos." ${ }^{35}$

Justamente por exercer a função de garantia da democracia no exercício da jurisdição constitucional, a Suprema Corte evita enfrentar questões de natureza claramente política e desenvolveu a doutrina das questões políticas. ${ }^{36}$

DWORKIN, por exemplo, defende a realização de uma leitura de moral política da Constituição pela Corte Suprema para garantir a proteção de direitos

up to the Civil War did not cast doubt on the legitimacy of constitutional government itself. They were the ordinary, even if ultimately violent, struggles of constitutional interpretation, rather than a sustained search for a fundamentally different principles of political document." JACOBSON, Arthur J. \& SCHLINK, Bernhard. Introduction. Constitutional Crisis. The German and the American Experience. IN: JACOBSON, Arthur J. \& SCHLINK, Bernhard (ed.). Weimar: a jurisprudence of crisis, p. 1.

34 A relevância do papel desempenhado pela Suprema Corte levou DWORKIN a afirmar que: "Os Estados Unidos são uma sociedade mais justa do que teriam sido se seus direitos constitucionais tivessem sido confiados à consciência de instituições majoritárias." (DWORKIN, Ronald. O império do direito, p. 426-427). O mesmo DWORKIN, logo em seguida, esclarece, em nota, que não tem como provar esta afirmação: "Não ofereço nenhum argumento para essa afirmação categórica; para fazê-lo, precisaria escrever outro livro. Teria de levar em conta, entre outras coisas, que os registros da Suprema Corte carecem de regularidade, que a instituições que chamo 'majoritárias' nem sempre ou nunca, como diriam alguns representaram as opiniões ou os interesses da maioria dos cidadãos, e que a Corte às vezes exerceu o poder que, como declarou Marshall, tornaria essas instituições mais majoritárias do que teriam sido de outro modo." (DWORKIN, Ronald. O império do direito, p. 427, nota 2).

35 SUNSTEIN, Cass R. Designing Democracy: what constitutions do, p. 10, no original: "In a deliberative democracy one of the principal purposes of a constitution is to protect not the rule of the majority but democracy's internal morality, seen in deliberative terms." Completando esta mesma idéia SUNSTEIN diz que "no seu ponto de vista, o objetivo central de uma constituição é criar as precondições para uma ordem democrática bem-funcionante, em que os cidadãos sejam capazes de governar a si mesmo." No original: "In my view, the central goal of a constitution is to create the preconditions for a well-functioning democratic order, one in which citizens are genuinely able to govern themselves." (SUNSTEIN, Cass R. Designing Democracy: what constitutions do, p. 6).

36 "In the U. S., there is one important limitation on the justificiability of constitutional claims, namely, that provided by the 'political question doctrine.' Although the contours of the doctrine are hardly clear and certain scholars have strongly criticized ist coherence (...), the political question doctrine has been regularly invoked by courts to refuse adjudicating certain types of constitutional claims. It must be emphasized that 
individuais (somente deles), como no caso do aborto (Roe v. Wade), em que o direito individual à privacidade foi desafiado e resolvido em favor da autonomia individual feminina para decidir sobre a interrupção da gravidez. ${ }^{37}$

Com efeito, não obstante a Suprema Corte desempenhe uma atividade judicial que se imiscui no debate democrático em uma leitura de moral política da Constituição, questões decisivas são deixadas de lado pelo Tribunal por terem natureza claramente política.

\subsubsection{O SISTEMA ROMANO-GERMÂNICO: A INTERVENÇÃO E A OBJE- TIVIDADE METODOLÓGICA DA ATIVIDADE JUDICIAL DO DIREITO CONSTITUCIONAL ALEMÃO}

O constitucionalismo alemão formou-se em torno da questão da proteção de direitos dos indivíduos contra o poder do Estado e da limitação do poder estatal. A teoria dos quatro status dos direitos fundamentais de JELLINEK reflete esta situação: todos os status (negativo, positivo, ativo e passivo) tratam da relação indivíduo e estado.

Na república de Weimar, o debate constitucional girava em torno, também, da limitação e da proteção dos indivíduos em relação ao Estado. Como a teoria constitucional era formulada em torno do direito estatal, a crise do estado representou o colapso da Constituição.

Com o advento da Lei Fundamental de 1949, a teoria constitucional passa a ser formulada em torno de um debate democrático em que a relação estado e indivíduo permanece importante; não mais a única a ser tratada.

De todo modo, a tradição de ênfase no controle do poder de um Estado intrinsecamente forte continuou a exercer influência no direito constitucional alemão. O debate sobre objetivos e métodos de Weimar transformou-se no debate sobre objetivos e métodos da aplicação judicial do direito pela Corte Constitucional alemã (Bundesverfassungsgericht). JACOBSON e SCHLINK resumem a evolução do direito constitucional alemão:

the doctrine is not meant to inhibit adjudication of politically charged constitutional issues. For example, the constitutional issues surrounding abortion have been highly politicized for a number of decades in the U.S. (...), but they are justificiable in the same way as all other individual rights issues arising under the Constitution. Instead the 'political question doctrine' must be understood in a more technical sense as defined by its many pronged nature. As the Court stated in Baker v. Carr (...)” DORSEN, Norman et. al. Comparative Constitutionalism: cases and materials, p. 137.

37 DWORKIN faz uma enfática defesa do direito individual ao aborto em artigo denominado "Roe Was Saved" (Roe foi salvo), referindo-se ao caso Planned Parenthood of Southeastern Pennsylvania et. al. v. Casey, em que três juízes nomeados por Presidente contrários ao direito de aborto votaram pela ratificação do precedente Roe v. Wade: DWORKIN, Ronald. Freedom's Law: the moral reading of the American constitution, p. 117-129. Para a compreensão aprofundada do ponto de vista de DWORKIN em relação ao aborto ver: DWORKIN, Ronald. Domínio da vida: aborto, eutanásia e liberdades individuais, $p$. 1- 94, 141-163 e 207-249. 
"Dois eventos no século levaram a uma decisiva marca na teoria do direito do estado na Alemanha: 'a luta sobre métodos e objetivos' (Methoden- und Richtungsstreit) durante o período de Weimar, e a introdução de extenso_controle judicial pelo Tribunal Constitucional Federal (Bundesverfassungsgericht) na República Federal." ${ }^{38}$

Para garantir a proteção do indivíduo e a legitimidade do Estado, desenvolveu-se um direito constitucional voltado para a existência de um intervencionismo judicial, cuja racionalidade e objetividade são garantidas por um método e por critérios previamente determinados. HÄBERLE, ao defender uma sociedade aberta dos intérpretes da Constituição, resume a situação da interpretação na Alemanha:

“A teoria da interpretação constitucional tem colocado até aqui duas questões essenciais:

- a indagação sobre as tarefas e os objetivos da interpretação constitucional, e

- a indagação sobre os métodos (processo da interpretação constitucional) (regras de interpretação)"39

Categorias teóricas orientadas para a garantia de objetividade, precisão e segurança na interpretação foram criadas e aprimoradas pela doutrina e pela jurisprudência. O princípio da proporcionalidade (acompanhado de seus três subprincípios: adequação, necessidade e proporcionalidade em sentido estrito $)^{40}$ é um bom exemplo desta pretensão de uma interpretação racional baseada em um critério objetivo. ${ }^{41}$

38 "Two events in this century have left a decisive mark on the theory of the law of the state in Germany: the 'struggle over methods and aims' (Methoden-und Richtungsstreit) during judicial control by the Federal Constitutional Court (Bundesverfassungsgericht) in the Federal Republic." JACOBSON, Arthur J. \& SCHLINK, Bernhard. Introduction. Constitutional Crisis. The German and the American Experience. IN: JACOBSON, Arthur J. \& SCHLINK, Bernhard (ed.). Weimar: a jurisprudence of crisis, p. 3.

39 HÄBERLE, Peter. Hermenêutica Constitucional. A sociedade aberta dos intérpretes da Constituição: contribuição para a interpretação pluralista e 'procedimental' da Constituição, p. 11.

40 Para a compreensão aprofundada da proporcionalidade e seus três subprincípios ver: PULIDO, Carlos Bernal. El Principio de Proporcionalidad y los Derechos Fundamentales: El principio de proporcionalidad como critério para determinar el contenido de los derechos fundamentales vinculante para el legislador, 686-798.

${ }^{41}$ Muitos outros exemplos poderiam ser apresentados, como: a lei de colisão (cujo resultado é uma relação de precedência condicionada), os direitos fundamentais na dimensão objetiva e subjetiva, as reservas legais (simples e qualificada), a técnica de interpretação conforme a Constituição, dentre outros. A teoria tridimensional da dogmática dos direitos fundamentais pode ser situada nesta tradição de objetividade e precisão do direito constitucional alemão. Esta teoria, contudo, foi apresentada nesta pesquisa em termos diferentes da formulação de ALEXY não só por abandonar a ênfase na dimensão analítica e propor uma outra compreensão da dimensão normativa, mas por toda teoria ser acompanhada de uma leitura procedimental do direito, baseada no paradigma do Estado Democrático de Direito de HABERMAS em Faktizität und Geltung, e na teoria procedimental da interpretação do direito, formulada a partir da teoria do direito como integridade de DWORKIN. 
O direito judicial, centrado na intervenção do Bundesverfassungsgericht $\mathrm{e}$ guiado por critérios técnicos de interpretação, adquiriu proeminência no modelo alemão. A própria teoria dos direitos fundamentais de ALEXY é um bom exemplo de uma teoria voltada para garantir a racionalidade e a objetividade da interpretação dos direitos fundamentais pela Corte Constitucional alemã.

Hoje, o sistema alemão vive um dilema. $\mathrm{O}$ direito jurisprudencial adquiriu proeminência, mas a doutrina constitucional interpreta as decisões da Corte Constitucional alemã como se fosse um direito orientado exclusivamente pela tradição sistemática, como bem resume SCHLINK:

"O Tribunal Constitucional Federal desenvolveu o case law, e age de uma maneira crescentemente política. Em contraste, acadêmicos constitucionalistas dão continuidade ao estilo tradicional dos juristas dogmáticos germânicos que interpretam e aplicam o direito codificado, e então esperam que os juízes sejam a voz da lei, aplicando nas suas decisões uma lei que não criaram, mas simplesmente encontraram. Não há espaço nesta tradição para a discussão acadêmica com o Tribunal Constitucional Federal que envolvendo argumentos políticos, ou concentrando-se em casos individuais, examine como os problemas sociais do caso surgiram, e orientando se o problema foi corretamente resolvido pelo Tribunal Constitucional Federal. (...) A doutrina prefere canonizar as decisões do Tribunal Constitucional Federal. Ela lê e interpreta estas decisões, e as suas razões, como se fosse direito codificado." ${ }^{42}$

Como se pode ver pela sucinta exposição das experiências constitucionais alemã e americana, a internacionalização dos direitos humanos e a influência recíproca das Cortes Constitucionais, não impediu a formação de tradições constitucionais muito diferentes, que refletem modos especiais de ver o direito nos dois mais influentes sistemas jurídicos do ocidente. A compreensão destas tradições é imprescindível para a compreensão do direito constitucional brasileiro que sofre uma antiga e crescente influência do direito constitucional americano e alemão.

42 SCHLINK, Bernhard. German constitutional culture in transition. In: ROSENFELD, Michel (ed.). Constitutionalism, Identity, Difference, and Legitimacy: Theoretical Perspectives, p. 220-221, no original: "The Bundesverfassungsgericht hás propelled the development of case law forward, and acts in an increasingly open manner politically. In contrast, constitucional scholarship that interprets and applies codified law, and then expects judges to be the voice of the law, applying in their decisions a law that they have not made, but have simply found. There is no place in this tradition for a scholarly discourse with the Bundesverfassungsgericht that involves political arguments, or concentrates on an individual case, examines how the case's social problem evolved, and addresses whether the problem was correctly solved by the Bundesverfassungsgericht. (...) It rather canonizes the decisions of the Bundesverfassungsgericht. It reads and interprets these decisions, and their reasoning, as though they were codified law." 


\section{A INTERPRETAÇÃO DOS DIREITOS FUNDAMENTAIS NO BRASIL: CAMINHOS}

Já se demonstrou que o Brasil sempre foi aberto para a influência de sistemas jurídicos estrangeiros (do inglês e do francês, passando pelo americano até chegar para o alemão, apenas para citar alguns dos mais relevantes). Em seguida, verificou-se que no direito constitucional brasileiro atual, o direito constitucional americano (maior representante do sistema do common law e do judicial review) e o direito constitucional alemão (maior representante do sistema do statute law e do controle concentrado de constitucionalidade) são os que possuem ascendência mais determinante.

Por fim, demonstrou-se que ambos os sistemas partem, historicamente, de compreensões diferentes do direito constitucional das quais resultaram dois modos de interpretação da constituição: 1) o americano em que o debate constitucional faz parte do debate público; 2) o alemão voltado para a objetividade na interpretação judicial do direito.

Agora, resta compreender qual o modelo de interpretação constitucional deve ser seguido pelo Brasil: o americano, o alemão ou um outro modelo? Esta pergunta é importante para que se possa encontrar a resposta para outra pergunta que acompanha toda estas pesquisa: qual modelo constitucional deve ser adotado no Brasil para a interpretação dos direitos fundamentais? ${ }^{43}$

A própria história constitucional brasileira, marcada pela influência de diversos países (a formar quase um "sincretismo constitucional"), já demonstra que seria difícil, em nossa realidade, adotar integralmente o modelo americano ou o modelo alemão.

Na jurisprudência do Supremo Tribunal Federal, verifica-se a influência do direito alemão e das decisões do Bundesverfassungsgericht ao lado da influência do direito americano e das decisões da Supreme Court. Na doutrina brasileira, há, igualmente, autores influenciados por um ou por ambos os modelos.

Neste contexto, o direito constitucional brasileiro precisa apropriar-se das contribuições americana e alemã, reformulando-as e as adequando para a nossa realidade. Por isso, foi tão importante a exposição, ainda que extremamente sucinta, do direito constitucional alemão e americano.

$\mathrm{O}$ direito constitucional alemão enfatiza excessivamente a intervenção judicial e a suposta objetividade de sua interpretação, o que é contestado com veemência na própria Alemanha. HABERMAS, em sua contundente crítica a esta

\footnotetext{
${ }^{43}$ A resposta para estas perguntas não é evidente e certamente mudará de acordo com o direito pressuposto pelo pesquisador. Não se pretende aqui buscar uma resposta definitiva para esta pergunta e uma resposta adequada exigiria a reconstrução do constitucionalismo brasileiro, que exigiria a leitura e compreensão dos autores clássicos e contemporâneos da história e do direito constitucional brasileiro. Semelhante empreendimento foge muito do objetivo da presente pesquisa, embora se reconheça a inegável utilidade e necessidade de uma pesquisa desta natureza.
} 
posição, denominou-a de crítica a uma auto-compreensão metodológica falsa do controle de constitucionalidade, afirmando que:

“As reservas contra a legitimidade da jurisprudência do Tribunal Constitucional Federal não dependem apenas da mudança de paradigmas, mas também de concepções metodológicas. Na República Federal da Alemanha, a crítica pode referir-se a uma 'doutrina da ordem de valores', desenvolvida pelo próprio tribunal, portanto a uma autocompreensão metodológica dos juízes, a qual teve conseqüências problemáticas para a decisão de importantes precedentes, o que não acontece nos Estados Unidos. A crítica justificada à jurisprudência dos valores dirige-se, muitas vezes de forma brusca, contra as graves conseqüências que resultam do Estado de direito, sem esclarecer que se trata apenas, e em primeiro lugar, de conseqüências de uma auto-interpretação falsa. Com isso, ela perde de vista a alternativa de uma compreensão correta da interpretação, segundo a qual, direitos não podem ser assimilados a valores."44

O direito constitucional americano negligencia a importância da intervenção judicial na proteção de direitos sociais e em questões políticas para privilegiar o fortalecimento de uma democracia deliberativa em que a interpretação constitucional reflete o debate político.

Apropriando-se das contribuições e das críticas de ambos os modelos, o presente texto pretende compreender os direitos fundamentais utilizando os critérios alemães que guiam a jurisprudência interventiva da Corte Constitucional sem negligenciar a importância da abertura do debate constitucional travada na Corte Suprema para a sociedade, como ocorre nos Estados Unidos e na Suprema Corte, e hoje é reconhecido até mesmo na Alemanha na formulação da sociedade aberta dos intérpretes da Constituição de HÄBERLE. ${ }^{45}$ De acordo com HÄBERLE:

${ }^{44}$ HABERMAS, Jürgen. Direito e Democracia: entre facticidade e validade, Volume 1, p. 314-315. Esta questão será rediscutida posteriormente na presente pesquisa.

45 GILMAR FERREIRA MENDES, tradutor de HÄBERLE no Brasil e hoje Ministro do Supremo Tribunal, resume a importância desta obra para o direito constitucional: "Häberle propugna pela adoção de uma hermenêutica constitucional adequada à sociedade pluralista ou à chamada sociedade aberta. Tendo em vista o papel fundante da Constituição para a sociedade e para o Estado, assenta Häberle que todo aquele que vive a Constituição é um seu legítimo intérprete. (...) Evidentemente, essa abordagem tem conseqüências para o próprio processo constitucional. Häberle enfatiza que os instrumentos de informação dos juízes constitucionais devem ser ampliados e aperfeiçoados, especialmente no referente às formas gradativas de participação e à própria possibilidade de interpretação no processo constitucional (notadamente nas audiências e nas 'intervenções'). Impõe-se, pois, para Häberle, um refinamento do processo constitucional, de modo a se estabelecer uma comunicação efetiva entre os participantes desse processo amplo de interpretação. Portanto, o processo constitucional torna-se parte do direito de participação democrática.”(HÄBERLE, Peter. Hermenêutica Constitucional. A sociedade aberta dos intérpretes da Constituição: contribuição para a interpretação pluralista e 'procedimental' da Constituição, p. 9-10) 


\begin{abstract}
"O Direito Constitucional material vivido surge de um número enorme de funções 'corretamente' exercidas: aquelas desempenhadas pelo legislador, pelo juiz constitucional, pela opinião pública, pelo cidadão, mas também pelo Governo e pela oposição. Essa reflexão sobre a interpretação constitucional demonstra que, de uma perspectiva constitucional-processual, correção funcional da interpretação constitucional leva praticamente a uma diversidade da interpretação constitucional. A interpretação correta depende, pois, de cada órgão, do procedimento adotado, de sua função e de suas qualificações. ${ }^{46 "}$
\end{abstract}

A proposta apresentada aqui não pretende ser, contudo, um guia para a compreensão dos direitos fundamentais, mas tão somente se resume a compreender os direitos fundamentais no Estado Democrático de Direito, instituído com o advento da Constituição brasileira de 1988.

De todo modo, o modelo escolhido deverá ter a pretensão de superar as deficiências do modelo alemão e americano e ser apto para uma compreensão adequada do direito constitucional brasileiro.

Neste contexto, a interpretação e a intervenção judicial devem ser valorizadas no contexto de uma sociedade aberta dos intérpretes da Constituição pois, segundo o ministro do Supremo Tribunal Federal GILMAR MENDES, ao apresentar a obra de HÁBERLE:

"Essa concepção exige uma radical revisão da metodologia jurídica tradicional, que, como assinala Häberle, esteve muito vinculada ao modelo de uma sociedade fechada. A interpretação constitucional dos juízes, ainda que relevante, não é (nem deve ser) a única. Ao revés, cidadãos e grupos de interesse, órgãos estatais, o sistema público e a opinião pública constituiriam forças produtivas de interpretação, atuando, pelo menos, como pré-intérpretes (Vorinterpreten) do complexo normativo constitucional." ${ }^{47}$

A formação de um modelo constitucional que se situa entre as duas escolas partirá no presente caso da teoria procedimental do Estado Democrático de Direito para a teoria dogmática dos direitos fundamentais em suas três dimensões: analítica (sistemático-conceitual), empírica (centrada no direito positivo legal e jurisprudencial) e normativa (que permite a discussão da dogmática sob a égide do paradigma procedimental e da teoria procedimental).

46 HÄBERLE, Peter. Hermenêutica Constitucional. A sociedade aberta dos intérpretes da Constituição: contribuição para a interpretação pluralista e 'procedimental' da Constituição, p. 52.

47 MENDES, Gilmar Ferreira. Apresentação. In: HÄBERLE, Peter. Hermenêutica Constitucional. A sociedade aberta dos intérpretes da Constituição: contribuição para a interpretação pluralista e 'procedimental' da Constituição, p. 9. 
Um modelo brasileiro somente terá êxito se levar a sério a construção de uma teoria constitucional adequada para a nossa realidade que leve em consideração as vantagens das teorias e dos modelos alemão e americano.

Parafraseando SCHLINK pode-se afirmar, em relação ao direito constitucional brasileiro, que: algo de novo está emergindo no Brasil. Talvez algo entre o modelo romano-germânico do Brasil (inspirado no modelo alemão) da tradição de codificação e sistematização da jurídica e o modelo americano do case law, este 'algo' irá adquirir a sua forma. ${ }^{48}$

Encontrar este 'algo' é a grande tarefa de todos os constitucionalistas e da sociedade aberta dos intérpretes da Constituição. Aqui, não pretendo apresentar uma solução para esta grande questão, mas apenas apresentar um caminho possível, pois como afirma MARTIN HEIDEGGER: "No pensamento, o que permanece é o caminho. E os caminhos do pensamento guardam consigo o mistério de podermos caminhá-los para frente e para trás, trazem até o mistério de o caminho para trás nos leva para frente." 49

\section{REFERÊNCIAS}

ALEXY, Robert. Teoría de los derechos fundamentales de Tradução Ernesto Garzón Valdès. Madrid: Centro de estudios políticos y constitucionales, 2001. Theorie der Grundrechte.

BOBBIO, Norberto. A Era dos Direitos. Trad. Carlos Nelson Coutinho. Rio de Janeiro: Campus, 1992. Título original: L'età dei Diritti.

BONAVIDES, Paulo. Curso de Direito Constitucional. 11 ed. São Paulo: Malheiros, 2001.

BONAVIDES, Paulo \& ANDRADE, Paes de. História Constitucional do Brasil. Brasília: OAB editora, 2002.

CANOTILHO, José Joaquim Gomes. Direito Constitucional e Teoria da Constituição. 2. ed. Coimbra: Almedina, 1998.

${ }^{48}$ A frase de SCHLINK é a seguinte: "Something new is emerging in Germany. Perhaps somewhere between the German tradition of codified, systemized law and the American idea of case law, this 'something' will take its form." SCHLINK, Bernhard. German constitutional culture in transition. In: ROSENFELD, Michel (ed.). Constitutionalism, Identity, Difference, and Legitimacy: Theoretical Perspectives, p. 222.

${ }^{49}$ HEIDEGGER, Martin. A Caminho da Linguagem. Tradução de Márcia Sá Cavalcante Schiback. Petrópolis-RJ e Bragança Paulista-SP: Editora Vozes e Editora São F 
CAPPELLETTI, Mauro. O controle judicial de constitucionalidade das leis no direito comparado. Trad. Aroldo Plínio Gonçalves. 2. ed. Porto Alegre: Sergio Antonio Fabris Editor, 1984. Título original: Il controllo giudiziario di constituzionalità delle leggi nel diritto comparato.

CARVALHO NETTO, Menelick de. A hermenêutica constitucional sob o paradigma do Estado Democrático de Direito. In: OLIVEIRA, Marcelo Andrade Cattoni de (coord.). Jurisdição e Hermenêutica Constitucional no Estado Democrático de Direito. Belo Horizonte: Mandamentos, 2004, p. 25-44.

COELHO, Inocêncio Mártires. Interpretação Constitucional. Porto Alegre: Sergio Antonio Fabris Editor, 1997.

DORSEN, Norman et al. Comparative Constitutionalism: cases and materials. S. Paul: Thomson West, 2004.

DWORKIN, Ronald. Freedom's Law: a Moral Reading of the American Constitution. New York: Oxford University Press, 1996.

. O Domínio da Vida: aborto, eutanásia e liberdades individuais. Trad. Jefferson Luiz Camargo. São Paulo: Martins Fontes, 2003. Título original: Life's Dominion.

. O Império do Direito. Tradução de Jefferson Luiz Camargo. São Paulo: Martins Fontes, 1999. Título original: Law's empire.

. Uma Questão de Princípio. Trad. Luís Carlos Borges. São Paulo: Martins Fontes, 2001. Título original: A matter of principle.

GADAMER, Hans-Georg. Verdade e Método: Traços fundamentais de uma hermenêutica filosófica. Trad. Flávio Paulo Meurer. 4. ed. Petrópolis: Vozes, 2002. Título original: Wahrheit und Method.

GALINDO, George Rodrigo Bandeira. Tratados internacionais de direitos humanos e constituição brasileira. Belo Horizonte: Del Rey, 2002.

HÄBERLE, Peter. Hermenêutica Constitucional. A sociedade aberta dos intérpretes da Constituição: contribuição para a interpretação pluralista e 'procedimental' da Constituição. Trad. Gilmar Ferreira Mendes. Porto Alegre: Sérgio Antônio Fabris Editor, 1997. Título original: Die offene Gesellschaft der Verfassunsinterpreten. Ein Beitrag zur pluralistischen und 'prozessualen' Verfassungsinterpretation.

HABERMAS, Jürgen. Direito e Democracia: entre faticidade e validade. Trad. Flávio Beno Siebeneichler. Rio de Janeiro: Tempo Brasileiro, 1997. 2 v. Título original: Faktizität und Geltung. Beiträge zur Diskurstheoie des Rechts und des demokratische Rechstaats.

. Paradigms of Law. In: ROSENFELD, Michel; ARATO, Arato (Ed.). 
Habermas on Law and democracy: critical exchanges. Translated by William Reg. London, Berkeley and Los Angeles: University of California Press, 1998, p. 13-25.

HEIDEGGER, Martin. A Caminho da Linguagem. Trad. Márcia Sá Cavalcante Schiback. Petrópolis-RJ e Bragança Paulista-SP: Vozes e São Francisco, 2003, p. 81 .

HESSE, Konrad. A força normativa da Constituição. Trad. Gilmar Ferreira Mendes. Porto Alegre: Sergio Antonio Fabris Editor, 1991. Título original: Die normative kraft der Verfassung.

JACOBSON, Arthur J. \& SCHLINK, Bernhard. Introduction. Constitutional Crisis. The Germanl and the American Experience. IN: JACOBSON, Arthur J. \& SCHLINK, Bernhard (ed.). Weimar: a jurispurdence of crisis. Transleted by Belind Cooper et al. Berkeley, Los Angeles and London: University of California Press, 2002, p. 1-39.

KAUFMANN, Rodrigo de Oliveira. Dimensões e perspectivas da eficácia horizonta dos direitos fundamentais: possibilidades e limites de aplicação no direito constitucional brasileiro. Dissertação (Mestrado em Direito e Estado), Universidade de Brasília, Brasília, 2003.

KELSEN, Hans. Quién debe ser el defensor de la Constitución? Madrid: Tecnos, 1995.

LOCKHART, William B.et al. The American Constitution: cases, comments, questions. 8. ed. St. Paul: West Publishing Co., 1996.

LUÑO, Antonio-Enrique Pérez. Derechos Humanos, Estado de Derecho y Constitucion. 7. ed. Madrid: Editorial Tecnos, 2001. . Los Derechos Fundamentales. Madrid: Tecnos, 1988.

MENDES, Gilmar Ferrreita et al. Hermenêutica Constitucional e Direitos Fundamentais. Brasília: Brasília Jurídica, 2000.

. Direitos Fundamentais e Controle de Constitucionalidade: estudos de direito constitucional. São Paulo: Celso Bastos Editor, 1998.

PIEROTH, Bodo \& SCHLINK, Bernhard. Grundrecht. Staatrecht II. Heidelberg: C.F. Müller, 1998.

PULIDO, Carlos Bernal. El Principio de Proporcionalidad y los Derechos Fundamentales: El principio de proporcionalidad como critério para determinar el contenido de los derechos fundamentales vinculante para el legislador. Madrid: Centro de Estudios Políticos y Constitucionales, 2003. 
ROMERO DE VASCONCELOS, Eneas. Reforma Constitucional, Direitos Fundamentais e Cláusulas Pétreas: análise do art. 60, § 40, IV da Constituição. In: SILVA, Alexandre Vitorino et al. Estudos de Direitos Público: direitos fundamentais e estado democrático de direito. Porto Alegre: Síntese, 2003, p. 213-235.

SARLET, Ingo Wolfgang. A Eficácia dos Direitos Fundamentais. Porto Alegre: Livraria do Advogado, 1998.

SCHLINK, Bernhard. German constitutional culture in transition. In: ROSENFELD, Michel (ed.). Constitutionalism, Identity, Difference, and Legitimacy: Theoretical Perspectives. Durham and London: Duke University Press, 1994, p. 197-222.

SCHMITT, Carl. La Defensa de la Constitución. 2. ed. Traducción de Manuel Sanchez Sarto. Madrid: Tecnos, 1998.

SUNSTEIN, Cass R. Designing Democracy: what constitutions do. Oxford and London: Oxford University Press, 2001.

TRINDADE, Antônio Augusto Cançado. Tratado de Direito Internacional dos Direitos Humanos. 1. ed. Porto Alegre: Sergio Antonio Fabris, 1997. vol. 1. . A Proteção Internacional dos Direitos Humanos e o Brasil (19481997): as primeiras cinco décadas. 2. ed. Brasília: Editora da Unb, 2000.

VASCONCELOS, Arnaldo. Teoria da Norma Jurídica. São Paulo: Malheiros, 1995.

INTERPRETATION OF FUNDAMENTAL RIGHTS: WAYS FOR CONSTITUTIONAL HERMENEUTICS IN BRAZIL

Abstract: The present paper is about the interpretation of human rights in Brazil under the rule of Law. In order to understand the best way to interpret human rights under the Brazilian 1988 Constitution, we focus the historical development of the Brazilian constitutional system, comparing the influence of the American model (common law and judicial review) and the German model (statute law and concentrated constitutional review). In the end, we track ways for interpretation of human rights in Brazil.

Key words: Constitutional Law; Human Rights; Constitution; Interpretation; Brazil 